\title{
DISCURSOS SOBRE EL AGUA EN LA CUENCA DEL SEGURA: RAÍCES HISTÓRICAS, CONTINUIDADES Y CAMBIOS RECIENTES
}

\author{
Leandro del Moral Ituarte \\ Departamento de Geografía Humana \\ Universidad de Sevilla
}

\section{RESUMEN}

Partiendo de una reflexión conceptual y metodológica sobre análisis crítico de discursos y apoyándose en un trabajo de campo de dos años de duración, este estudio identifica los valores relativos al agua, el medio ambiente y el territorio en la cuenca del Segura, tomando como hipótesis de partida el carácter dominante del discurso de la 'modernización productiva'. Sobre esa base, el estudio presenta una caracterización discursiva de los actores y coaliciones sociales: sus narrativas y argumentaciones más frecuentes, insertas en un proceso histórico en continuo cambio; interpreta las formas con las que los diferentes actores contribuyen a reproducir o combatir las estrategias en presencia, y propone explicaciones de los conflictos, tratando de captar cómo éstos se despliegan en un contexto de discursos y prácticas concretas. El objetivo último del estudio es analizar los procesos y los factores de cambio en la cuenca del Segura en general y en la Región de Murcia en particular; captar la evolución, la adaptación y el 'aprendizaje institucional'; identificar las fracturas en las argumentaciones dominantes y los embriones e ingredientes de discursos emergentes, todavía no hegemónicos.

Palabras clave: agentes, conflictos, discursos sobre el agua, política hidráulica, cuenca del Segura, Región de Murcia

\section{ABSTRACT}

Drawing upon a conceptual and methodological reflection on discourse analysis and based on a two year intensive fieldwork, this study addresses the identification of values on water, environment and territory in the Segura river basin. It takes as initial hypothesis the dominant character of the discourse of 'productive modernization'. In parallel to this, the study develops a discursive characterization of social actors and coalitions, i.e., their more frequent narratives and technical and economic arguments, embedded 
in a historical process in constant change. On that basis, the study interprets the ways in which the different actors contribute to reproduce or to fight the confronting strategies in presence in the region. Furthermore, it presents explanatory proposals about the conflicts, trying to grasp how they are displayed in a historical context of concrete discourses and practices. The ultimate goal of the study is to analyze the processes and factors of change in the Segura river basin in general and in the region of Murcia in particular; to capture the evolution, adaptation and 'institutional learning'; to identify fractures in some key arguments and the embryos and ingredients of emerging, no yet hegemonic discourses.

Keywords: Stakeholders, conflicts, discourses on water, hydraulic policy, Segura river basin, Murcia region

\section{INTRODUCCIÓN}

En el año 2005 el Colegio de Geógrafos y la Secretaría General para el Territorio y la Biodiversidad, del Ministerio de Medio Ambiente, suscribieron un Convenio para la realización de investigaciones relativas a la relación entre los procesos territoriales y la demanda de recursos hídricos. Evolución reciente y tendencias en la cuenca del Segura, que fue coordinado por Santiago Fernández Muñoz y Antonio Prieto (Colegio de Geógrafos, 2008). El autor del presente capítulo fue el responsable del apartado dedicado al análisis de los aspectos socio-políticos y discursivos relacionados con dichos procesos ${ }^{1}$. Parte del trabajo realizado consistió en entrevistas a veintidós especialistas en la gestión del agua en la cuenca del Segura, entre los que se encontraba el profesor Alfredo Morales Gil, cuyas aportaciones fueron de especial importancia para la redacción del mismo. La revisión y actualización de ese trabajo, que nunca llegó a publicarse, valorando la consistencia de las conclusiones a las que entonces se llegó, a la luz del desarrollo de los acontecimientos desde aquella fecha hasta la actualidad, constituye el núcleo del texto que ahora se presenta.

\section{MARCO TEÓRICO, OBJETIVOS E HIPÓTESIS}

Entendemos por discurso un conjunto de ideas, conceptos y categorías, producidos, reproducidos y transformados a través en un serie de prácticas concretas, por medio de los cuales las realidades físicas y sociales cobran significado (Hajer, 1995). De acuerdo con Ernesto Laclau, lo discursivo se refiere al «conjunto de

1. Análisis de los discursos relacionados con los procesos territoriales que condicionan la presión sobre el agua en la cuenca del Segura, Coordinación y redacción: Leandro del Moral Ituarte. Documentación, entrevistas y trabajo de campo: Graciela Ferrer Matvieychuc, Ángela Espín Gutiérrez y Manuel Fernández García. Sevilla, 14 de abril 2007. Disponible en Research Gate http://researchgate.net/profile/Leando-Del-Moral. 
los fenómenos de la producción social de significado sobre el que se basa una sociedad. La cuestión no es que consideremos que lo discursivo es un plano o una dimensión de lo social, sino que es algo que tiene el mismo significado que lo social como tal. Por consiguiente, lo no discursivo no es lo opuesto de lo discursivo, como si tuviésemos que vérnoslas con dos planos diferentes, porque no hay nada societal que se encuentre determinado al margen de los discursivo» (Laclau, 1981 citado por Jäger, 2003, p. 74). Siempre teniendo en cuenta que, como señalaron Redclift y Woodgate (2002), el entorno no se puede representar simplemente por medio de la construcción social, a través del lenguaje o simbólicamente. Es también la condición y el producto material de la actividad humana. (cit. por Pedreño y Baños, 2006:375).

Algunas de las formas de generar significado, es decir, de producir discursos, son dominantes o mayoritarias en una formación social determinada; otras son marginales, o de oposición, o alternativas. El concepto político de hegemonía puede emplearse de forma provechosa para analizar los órdenes del discurso: una particular línea de discurso puede llegar a ser hegemónica, convirtiéndose en parte del sentido común legitimador que sustenta las relaciones de dominación, pero la hegemonía siempre será contrarrestada, en mayor o menos medida, mediante la lucha por la hegemonía. Un orden del discurso no es un sistema cerrado y rígido, sino más bien un sistema abierto expuesto a la dinámica de cambio consecuencia de las interacciones con otras visiones (Fairclough, 2003:183).

Si se quiere entender la estructura de conflictos como los que implican los procesos territoriales que tienen relación con el agua, no se pueden interpretar los intereses como una realidad dada, sino como una 'realidad constituida intersubjetivamente' a través del discurso. En este sentido, el lenguaje no es un simple conjunto de herramientas pasivas. No se puede comprender las percepciones y acciones sociales sin referencia al marco de 'sistemas de creencias' y 'universos simbólicos' profundamente enraizados en el que se sitúan, que se expresan en los discursos. Dentro de ellas, destacan el conjunto de símbolos colectivos o estereotipos culturales (topoi) que se transmiten y se utilizan de forma colectiva (Jäger, 2003, p. 65).

Frecuentemente, determinados actores que discrepan en algunos aspectos, pueden co-producir y compartir un discurso común en otros. El concepto de 'coalición discursiva' que empleamos en este estudio difiere del tradicional de 'coalición política' o 'comunidad de política' (aplicado en España al análisis de la política del agua por Víctor Péréz-Díaz, Josu Mezo y B. Álvarez-Miranda, 1996, y retomado en el Libro Blanco del Agua de 1998-2000) por su énfasis en las bases lingüísticas de los bloques o alianzas sociales (Hajer, 1995). Esas 'piezas nucleares' de los discursos, no solamente los intereses, forman las bases de las diferentes coaliciones. 
El análisis de los discursos aplicados a la compresión de los fenómenos socio-hidrológico se refiere a los procesos básicos en los que estos se materializan (recursos, demandas, usos, distribución, balances de agua, normativa, estructuras de gestión, etc.). Pero este tipo de análisis se centra en las maneras en las que estos hechos son entendidos, expresados y utilizados por los actores sociales implicados en la controversia sobre ellos (Van Dijk, 2003). Identifica -o confirma- temas clave; pone de manifiesto la resistencia de ciertas cuestiones a ser socialmente dadas por aclaradas; consigna y trata de interpretar las razones de la constitución de ciertos temas en focos de desacuerdo técnico y de conflictividad político-social permanente.

La aplicación de este marco conceptual al caso de la cuenca del Segura pretende servir para avanzar en:

a. La identificación de los valores relativos al agua, el medio ambiente y el territorio; tanto los permanentes como los que evolucionan, adaptándose a los cambios y emergiendo como nuevos puntos de referencia.

b. La caracterización discursiva de los actores y coaliciones sociales: sus expresiones, narrativas, argumentaciones técnicas y económicas más frecuentes a lo largo de un proceso de continuo cambio.

c. La explicación de los conflictos, situándolos en un plano más allá de la referencia exclusiva a los intereses, tratando de captar cómo éstos se despliegan en un contexto de discursos y prácticas organizativas específicos.

d. El entendimiento de las formas a través de las cuales los diferentes actores contribuyen a reproducir o combatir determinados prejuicios sin necesariamente orquestar o coordinar sus actuaciones o sin necesariamente compartir profundos valores comunes.

e. El análisis de dinámicas, procesos y factores de cambio, evolución, adaptación y 'aprendizaje institucional'. Embriones o ingredientes de discursos emergentes, no hegemónicos. Fracturas en las argumentaciones dominantes.

El punto de partida de la investigación ha sido la formulación de una serie de hipótesis generales sobre la composición, evolución y situación actual del ‘ideario hegemónico' en la cuenca, el 'paradigma hidráulico' en su manifestación concreta en la cuenca del Segura, que hemos denominado 'discurso de la modernización productivista' (Del Moral, 2000). El desarrollo posterior de la investigación ha permitido completar la identificación y definición de los acontecimientos y procesos clave en la construcción y evolución reciente de los discursos sobre el agua. Sobre esa base, se ha perfilado la estructura general del debate; se han identificado a los agentes sociales fundamentales; y se ha confirmado la definición de sus posiciones. Todo ello en paralelo a la tipificación 
inicial de las narrativas empleadas en la controversia pública, identificando algunos de los espacios y las prácticas en donde se producen los discursos.

Lo que interesa fundamentalmente en este estudio es comprender la dinámica, el cambio, las transiciones; descubrir qué argumentos se debilitan y cuáles emergen y se fortalecen; el sentido general del proceso histórico reciente; sus hitos más significativos; los acontecimientos emblemáticos. Interesa especialmente identificar a los agentes sociales fundamentales y los espacios desde donde se producen los discursos; los focos de creación de mensajes de adaptación del discurso hegemónico a las presiones de los nuevos factores que lo someten a tensiones. Es importante reconocer y valorar los núcleos de resistencia del discurso de la 'modernización productivista'. Nos interesa comprender su lógica, la potencia de sus símbolos, las razones de sus profundas y duraderas raíces sociales. Pero también, con tanto o mayor interés, los factores de desajuste con los cambios económicos, sociales, culturales; y en relación con ello, los factores de innovación, de crítica, de ajuste y de alternativa.

La reacción y renovación del paradigma hidráulico es el dato clave de la historia reciente de la cuenca del Segura y singularmente de la Región de Murcia. La identificación y explicación de sus componentes y dinamismo es el objetivo último de este estudio:

- ¿En torno a qué viejas/nuevas narrativas se reorganiza la defensa del 'discurso de la modernización hidráulica'?

- ¿Cómo se incorpora al paradigma la realidad de la industria del ocio y el turismo a gran escala, que no participa de la legitimidad incuestionada que tenían el regadío y los abastecimientos urbanos?

- ¿Mantiene el regadío -cualquier regadío- el mismo grado de legitimidad incontestable que ostentaba anteriormente?

- ¿Se producen fracturas discursivas en el 'bloque social de la modernización productivista'? Si esto fuera así, ¿en torno a qué argumentos se producen éstas?

La adopción de una perspectiva histórica es imprescindible en un estudio de este tipo. No se trata de contraponer diversos discursos, identificando sus rasgos distintivos y sus bases sociales contrapuestas. Se trata de hacer un seguimiento de un 'discurso base' desde su consolidación inicial, evolución, resistencia y adaptación. Un discurso hegemónico que se despliega en un proceso de 'radicalización discursiva' y, quizás, debilitamiento de su 'potencial estructurador e institucionalizador', hasta sus actuales manifestaciones. Paralelamente cabe preguntarse en qué medida las nuevas narrativas que han ido apareciendo consolidan una capacidad de generación de algún tipo de 'coalición discursiva' alternativa estable y duradera. 


\section{Metodologia Y FUENTES}

Todas las hipótesis y conclusiones iniciales, derivadas del reconocimiento del territorio, el análisis de la documentación, bibliografía, medios de comunicación audiovisual y escrita (un medio de ámbito nacional, El País, y tres de carácter regional, La Verdad, La Opinión y El Faro), las comparecencias de los 16 expertos consultados por la Comisión del Pacto del Agua, (noviembre 2006-marzo 2007), el Diario de Sesiones de la Asamblea de la Región de Murcia, etc., han sido sometidas a debate y retroalimentadas con entrevistas a una amplia batería de actores pertenecientes a las siguientes entidades:

- Confederación Hidrográfica del Segura.

- Administración regional (Secretaría General de Presidencia y Relaciones Externas, Consejería de Medio Ambiente, Consejería de Agricultura y Agua, Ente Público del Agua);

- Usuarios agrarios, urbanos e industriales (Sindicato Central de Regantes del Trasvase Tajo-Segura, Mancomunidad de Canales del Taibilla, Comunidades de Regantes);

- Asociaciones empresariales, sindicales y profesionales: Confederación de Organizaciones Empresariales de la Región de Murcia (CROEM), Federación de Cooperativas Agrarias de la Región de Murcia (FECOAM), Comisiones Obreras (CCOO), Confederación de Organizaciones Agrarias (COAG), ASAJA);

- Asociaciones ecologistas y ciudadanas (Ecologistas en Acción, Plataformas locales significativas, con especial atención a las correspondientes a la Vega Baja);

- Investigación y formación (Universidad de Murcia, Universidad Católica de Murcia, Universidad de Alicante, Instituto Euromediterráneo de Hidrotecnia);

- Medios de comunicación (La Verdad. La Opinión, El Faro, El País, revistas especializadas);

- Partidos políticos (PP, PSOE, IU, Podemos);

- Sectores económicos no agrarios claves (actividades del sector inmobiliario, residencial, ocio y turismo).

Se ha realizado entrevistas en profundidad a 22 actores sociales y expertos (una o dos a cada uno), seleccionados por su amplia perspectiva general desde diferentes posiciones. En todos los casos son profundos conocedores del caso de estudio; en general, en sí mismos son fuente de generación o difusión de discurso en diferentes planos discursivos; en algunos casos son actores de naturaleza individual, interviniendo en calidad de expertos; y en otros son representantes y 
portavoces de administraciones u otras entidades públicas o privadas (ver lista completa en Del Moral et al. 2007).

El Ámbito del trabajo: Cuenca del Segura, el sureste y la Región de MURCIA

El análisis de la cuenca del Segura, especialmente en términos de análisis de los discursos, plantea un singular problema de escalas y ámbitos espaciales, político-administrativos. Desde un punto de vista hidrográfico, sus límites y su carácter intercomunitario están fuera de cuestión, salvando la diferencia entre los conceptos de 'cuenca' y 'demarcación hidrográfica' (que incluye los cursos que vierten directamente al mar-cuencas intracomunitarias-y las aguas costeras), diferencia que en este caso no ha suscitado controversia. Sin embargo, desde el punto de vista de las percepciones sociales y los significados políticos, el especial peso de la Región de Murcia es indiscutible. Continuamente en la documentación, en la comunicación y en la representación se mezclan, se solapan y, frecuentemente, se identifican la cuenca del Segura y la Región de Murcia. El hecho es representativo de una realidad, más aguda que la que pueda representar, por ejemplo, el caso de Aragón en la cuenca del Ebro. Los límites de la actual Comunidad Autónoma de Murcia son recientes; en la etapa anterior a la actual estructuración autonómica del Estado, Albacete y Murcia constituían una región; el Sureste, con Alicante al norte y Almería al sur, se presentaba como un ámbito de referencia para los planteamientos de la política territorial y del agua (Morales et al., 1996, Calvo García-Tornel, 1984). Murcia como tal tenía una existencia simbólica y afectiva relativamente débil, como denominación administrativa de lo que en realidad era más un conjunto de grandes términos municipales/comarcas con personalidades muy acusadas, agrupados en un marco administrativo común (entrevistas a Pérez Picazo y Calvo GarcíaTornel, 2006).

La planificación del trabajo de campo realizado para este estudio tuvo en cuenta esta realidad, evitando simplificaciones y reduccionismos. Las tierras de la cabecera de la cuenca y las realidades de la Vega Baja han sido consideradas de una manera diferenciada. Se han confirmado acusados contrastes de percepción, valores y objetivos. Las situaciones se ajustan a los modelos habituales de conflictos de usuarios de aguas arriba/aguas abajo, pero muy complejizados por superposición de derechos, de procedencia histórica y naturaleza jurídica diferente, sobre aguas superficiales de la propia cuenca, sobre aguas procedentes del trasvase Tajo-Segura y sobre aguas subterráneas, con una casuística complicada de situaciones especialmente conflictivas (Gil Olcina, 2000). Por otra parte, se ha testado y matizado la hipótesis sobre el papel que los discursos actuales sobre el agua pudieran desempeñar en la configuración de una nueva o refortalecida 
personalidad colectiva murciana, a través del relanzamiento, en términos de confrontación, de la reclamación histórica de recursos externos.

\section{ELEMENTOS CONSTITUYENTES, ETAPAS, CRISIS Y REFORTALECIMIENTO DEL} DisCURSO HIDRÁULICO EN LA CUENCA DEL SEGURA²

\section{Discurso base: el paradigma hidráulico o el discurso de la 'modernización productiva'}

El Sureste Español no tendrá nunca desarrollo mientras no se apague la sed (eslogan de las reuniones del Consejo Económico Sindical Interprovincial del Sureste, 8 de noviembre de 1966).

Una característica fundamental de la cuenca del Segura es la presencia y persistencia de un discurso sólidamente articulado y profundamente enraizado en la sociedad y en el territorio. Un discurso fundado en una relación sociedadnaturaleza secularmente definida por el antagonismo y la amenaza, con la consiguiente percepción y justificación social de un objetivo prioritario y básico, apenas cuestionado: la trasformación y dominación de un medio físico hostil. Un discurso que hemos estudiado referido a otros ámbitos, como el estuario del Guadalquivir, también paradigmático para la interpretación de la dinámica de estas relaciones (Ojeda y del Moral, 2005). Pero sin duda en la cuenca del Segura, el enfoque de transformación y dominación adquiere rasgos y persistencias especialmente acentuados.

«Tierra sedienta, tierras áridas, resecas, peladas convertidas en verdaderos vergeles», se lee en el prólogo titulado «Nuestra cultura del agua: un compromiso secular», escrito por el Presidente de la Región de Murcia para una publicación de gran difusión, Murcia y el agua. Historia de una Pasión, 2006 (http://servicios.laverdad.es/murcia_agua/firmas.htm).

Partimos de una hipótesis general de interpretación: la constitución inicial del ideario dominante, del 'discurso base', en el momento del lanzamiento del proyecto de Trasvase Tajo-Segura (en la segunda mitad de la década de 1960). De una manera puramente convencional situamos en ese momento la cristalización de un ideario profundamente enraizado en el imaginario colectivo regional, que se caracteriza por estar construido con materiales discursivos y simbólicos procedentes de etapas históricas muy anteriores: la supervivencia colectiva vinculada a la transformación de un medio hostil, del que se transmite una imagen especialmente conflictiva y negativa.

2. Ver desarrollo completo de los materiales y análisis discursivo realizado en Del Moral et al. 2007). 
Si se exceptúa la estrecha franja de aluvión por la que discurre el río Segura y en la que tradicionalmente ha existido un cultivo de huerta y por tanto la consecuente riqueza, todo el sureste español desde Alicante hasta Almería ha sido víctima de una sed ancestral reflejada en el estrangulamiento de cualquier actividad económica» («Canales del Taibilla, fuente del desarrollo del sureste español, El País, 18 de julio de 1990).

El argumento del carácter fundamental del regadío para la economía aparece como pieza clave de este relato: una prioridad regional coherente con el interés nacional debido a las ventajas competitivas del Sureste sobre otras regiones peninsulares; la imagen de los regadíos tradicionales como ejemplo y concreción de un mundo rural productivo y cohesionado que hace buen aprovechamiento de los recursos, especialmente del agua; el desarrollo de una producción agraria intensiva, de la que depende una pujante actividad de comercialización y transformación agroindustrial.

A esto se suma la penuria y la solución eficaz de los graves problemas de abastecimiento urbano: la Mancomunidad de Canales del Taibilla y el buen hacer en la gestión del 'agua para beber', argumento con profundas raíces en la trayectoria del reformismo modernizador.

\section{Los primeros elementos de perturbación del paradigma hidráulico en la década de 1970}

Este potente discurso de la 'modernización productiva' vinculada al paradigma hidráulico se va viendo sometido a un proceso de perturbación, con la progresiva aparición de realidades y debates que van afectando a algunos de sus fundamentos. Hemos identificado los primeros elementos de perturbación a los que este ideario dominante se vio sometido a partir de la segunda mitad de los años 70 , como consecuencia de factores económicos, sociales y políticos, con implicaciones ambientales y culturales: la crisis del regadío tradicional y la ocupación urbanística de la Huerta, que provoca la reducción y progresiva desaparición de los regadíos históricos ('la muerte de la huerta'); la profunda diferenciación, que no hará más que profundizarse en las décadas posteriores, de los nuevos espacios regados, las nuevas estructuras productivas y los nuevos protagonistas.

... la pérdida de valor del suelo agrícola frente al urbanizable ha destruido las antiguas huertas periurbanas en un proceso rápido y mal gestionado, que no ha permitido la preservación de un valioso patrimonio histórico, cultural y antropológico sino en sus términos más banales. Quizá el caso de la Huerta de Murcia sea el ejemplo más paradigmático (Calvo García-Tornel, 2006: 15.).

El desarrollo socioeconómico de Murcia y su huerta en los últimos años parece alejarla ya de su forma de ser, hasta el extremo de que algunos intelectuales y grupos ecologistas han lanzado frases como la «Huerta se muere (Morales Gil, 2001: 73-77). 
La idea que mantenemos es que el paradigma hidráulico hegemónico experimenta una interacción con procesos que lo van erosionando, como la emergencia de los problemas de degradación del agua, del medio ambiente y los paisajes del agua; las primeras reacciones sociales importantes al profundo deterioro de la calidad de agua -'la polución'- y del medio acuático, especialmente en la Vega Baja.

Yo llevaba a mis hijos a lugares que ahora están secos» [con tono neutro, sin manifestación de crítica; sin manifestación de dolor, de pérdida; constatando una situación incuestionable]. «No hay que enfrentar el idealismo al realismo, a la calidad de vida, al desarrollo, al empleo (Entrevistado con importantes responsabilidades en la gestión económica en el ámbito de estudio).

Hace ya bastantes años, a finales de los 70 , se intentó organizar un movimiento cívico que luchara por impedir el grave deterioro a que estaba sometido el río Segura [...] Nuestra principal fuente de vida y riqueza había iniciado un proceso de degradación, fruto de la contaminación y de la sobreexplotación, que pondría a corto y medio plazo en peligro nuestra tierra, nuestra economía y nuestra salud (José Manuel López Grima, miembro destacado de la Comisión Permanente de la Plataforma Segura Limpio).

Todo ello da lugar a cambios de relaciones internas en la 'coalición discursiva' del paradigma hidráulico, aunque se mantiene la cohesión y la unidad de objetivos interna básica.

\section{El paradigma hidráulico desarrolla y actualiza sus argumentos en el nuevo marco constitucional de 1978}

Pero frente a este proceso de erosión, el discurso modernizador va adaptándose con nuevos o reactualizados ingredientes y argumentos: la transformación/continuidad de la cultura tradicional del uso del agua en forma de nueva 'eficiencia técnica y económica' en la gestión del recurso; el dinamismo de la iniciativa empresarial y la inversión privada, la introducción de nuevas tecnologías («Regar con microprocesador», El País, 17-6-1985); la expansión de nuevos regadíos que consolidan la producción para los mercados exteriores y refuerzan la competitividad, en ausencia de subvenciones; la autofinanciación del regadío a partir de aguas subterráneas y tarifas recuperadoras de costes en el suministro de aguas superficiales a los nuevos regadíos.

El sector agroalimentario murciano es uno de los pilares básicos del crecimiento de la economía regional. Es un sector competitivo, poco subvencionado y eminentemente exportador [...] presenta un notable proceso de especialización agrícola, un elevado índice de empleo agrario y una explotación más bien pequeña de tipo familiar. [...]. (Ramón Luis Valcárcel, Presidente del Gobierno Regional, La Verdad, 29 de abril de 2002). 
Se reactualizan los argumentos sobre la creación de puestos de trabajo, que dependen de la disponibilidad de las aportaciones de agua del exterior, núcleo de cohesión de los diferentes sectores sociales de la 'coalición discursiva' en esta etapa y en las posteriores.

[...] el impacto de la falta de agua sobre la renta agraria regional ocasionaría en los próximos 50 años unas pérdidas de 6.000 millones de euros (un billón de pesetas, que representaría el desmontaje y la ruptura de la economía murciana [...] La Región sufrirá una reconversión brutal si no llega el trasvase del Ebro [...] se resentiría el $35 \%$ del empleo regional, ante la fuerte dependencia de la agricultura que mantiene toda la actividad económica de Murcia. (José Luis Romero (CCOO) y Víctor Meseguer (UGT), en La Opinión de Murcia, 14 de mayo de 2002).

En esta etapa se produce, también, la 'cientifización' de la tradicional visión hostil del territorio a través del concepto de 'desertificación', como nuevo soporte de la tradicional visión amenazante del territorio (Martínez y Esteve, 2005).

Es bien sabido que las regiones meridionales del Mediterráneo han venido sufriendo desde el remoto pasado los envites reiterados de la aridez [...] este drama ha venido a extenderse con carácter de alarmante gravedad hasta nuestro territorio y, en el curso de los últimos decenios, su representación ha experimentado un nuevo paroxismo; como si el Sahara, despertándose de un prolongado letargo, hubiese decidido ensancharse a lo largo de todas sus fronteras [...] Pero la tragedia que se cierne sobre el Sureste ha de ser evitada a toda costa. El trasvase constituye una pieza esencial para conseguirlo» (Alvargonzález, «El drama del Sureste, El País, 28 de mayo de 1980).

«Se está desertizando la región», señala el consejero de Agricultura, José Luis Albacete, «y si al final no llega el agua prevista del trasvase, el millón de habitantes que tiene la región tendrá que ir pensando en marcharse.» («Murcia, supeditada a la angustiosa espera del agua», 6 de julio de 1984).

\section{Nuevos factores de crisis del paradigma hidráulico en el cambio de siglo}

Más adelante, en un proceso continuo sin límites cronológicos tajantes, identificamos una segunda oleada de elementos de perturbación que se desarrollan con intensidad creciente desde el debate sobre el primer proyecto de Plan Hidrológico Nacional (1993-1995). Emergen nuevas preocupaciones -armas arrojadizas en la controversia social- acerca del descontrol sobre los usos (extensión de las superficies regadas, volumen de los recursos utilizados), y sobre la ilegalidad de los aprovechamientos; controversia sobre ampliación de superficies regadas, acentuación de los problemas de falta de control y la percepción social cada vez más clara de estas realidades.

Las discrepancias entre las cifras publicadas son frecuentes, y no sólo entre el Censo Agrario y los Anuarios de Estadística Agraria que publica el Ministerio 
competente, sino así mismo entre estos y la estadística producida por la Comunidad Autónoma de Murcia (Calvo García-Tornel, 1999: 497).

Una estimación conservadora daría un incremento para los últimos años de unas 3.000-4.000 hectáreas anuales en Murcia [...] La contestación oficial a este crucial asunto resulta paradigmática: se dice que no hay más roturaciones para regadío porque no hay agua con qué regarlas. Siempre se responde en este sentido: ¿de dónde sale el agua para los regadíos ilegales? La solución es simple: el agua sale del mismo sitio de que ha salido para el actual déficit, de los acuíferos con su mercado negro de compra-venta (Foro Ciudadano Región de Murcia, 2003: 87).

Se inicia el análisis de los efectos de la modernización de regadíos sobre consumos netos de agua: aumenta la eficiencia pero no disminuye el consumo total, sino a veces al contrario ('efecto rebote'). La pérdida de peso de la agricultura en la economía nacional y regional empieza a propiciar la revisión crítica de la rentabilidad económica y social del reparto sectorial del agua. Se intensifican los cambios en las estructuras productivas y en la composición social del sector agrario: consolidación del modelo empresarial avanzado, el agro-business; nueva estructura del mercado de trabajo, inmigración irregular, cambios sociodemográficos y culturales, controversias sobre las condiciones de trabajo; intensificación o emergencia de nuevas formas de conflictividad entre diferentes sectores del regadío (regadíos tradicionales/nuevos regadíos).

«En Murcia necesitamos un freno de emergencia». P.-¿Qué impresión tiene la sociedad murciana sobre los nuevos regadíos? R.-Se están empezando a mirar con preocupación los efectos sociales y ambientales del modelo agrícola. Pero también es cierto que mucha gente vive con las puertas bien cerradas para no ver nada. P.- ¿Y la huerta tradicional? R.-La huerta tradicional es la gran perdedora. Secanos y huertas tradicionales todavía tienen un potencial por descubrir para definir un nuevo modelo de producción agropecuario de calidad. Por ahora, la locomotora de la agricultura industrial hegemoniza el territorio, usurpa el agua a los regadíos tradicionales y, sobre todo, encandila al poder político, impidiendo cualquier debate» (entrevista a Andrés Pedreño, Heraldo de Aragón, lunes 29 de enero de 2001).

Se intensifican los problemas, las respuestas sociales y los conflictos por la contaminación y el deterioro del medio en las Vegas del Segura, que pasa de problema 'ambiental' a problema 'sanitario'; socialización (generalización) de la protesta en determinadas áreas de la cuenca.

... en el lecho del río únicamente circulan aguas residuales urbanas e industriales a las que se suman las procedentes de filtraciones de las tierras de regadío circundantes, que lo convierten en un foco de infecciones, contaminación hídrica e incluso atmosférica (Morales Gil, 2001: 225). 
Lejos quedan esas idílicas imágenes de Orihuela en las que se puede contemplar a los vecinos de la ciudad monumental en la ribera del Segura, debajo del puente de Levante, en pleno centro urbano, paseando e incluso bañándose. Ahora la imagen es bien distinta, apenas hay agua en el cauce y sí mucha suciedad [...] Pero el problema no sólo se sufre en Orihuela. Las poblaciones de Almoradí, Benejúzar, Rojales, Guardamar ven cómo la situación del río se agrava a medida que se acerca a la desembocadura. («La Comisión Pro-Río denunciará ante la Fiscalía la contaminación que sufre el río Segura», El País, 30 de abril de 1999).

La mutitudinaria manifestación en Madrid constituyó un rotundo éxito al llevar a Madrid a más de 14.000 personas, en su inmensa mayoría de la Vega Baja. (José Manuel López Grima, Comisión Permanente de la Plataforma Segura Limpio, 2000).

Impacto de la nueva fase de expansión urbanística-residencial-sector del ocio y turismo y su aparición como foco de demanda de importancia creciente en el reparto de los recursos hídricos, que se percibe con visión crítica desde el exterior de la región.

Será preciso buscar soluciones consensuadas puesto que las actividades agrarias deben ser defendidas frente a la terciarización que amenaza las economías mediterráneas de la mano de un nuevo ciclo económico que ya ha demostrado su capacidad depredativa: el desarrollo de un urbanismo de signo turístico («Introducción histórica», en Senet y Cabeza, 1995: 36).

... las funciones turísticas y de ocio (se han convertido) en factor conflictivo, aunque fundamental, que condiciona el cambio de prioridad en la asignación de recursos naturales en el contexto de la economía regional (Vera Rebollo, 1987, cit. por Garulo Muñoz, 1997).

¿Dónde queda aquí el regante tradicional, referente capital de nuestra «solidaria» demanda de agua a cualquier tierra lejana en la que no se gaste con fines productivos todo el caudal disponible? Nuestro referente real debería ser un empresario agro-urbanístico, con sus despachos y abogados, sus inmigrantes explotados y sus terrenos en vías de recalificación urbanística (Foro Ciudadano Región de Murcia, 2003: 88).

Todo ello contribuye a debilitar ciertos 'mitos' de este paradigma ('identificación solidaria del conjunto de la sociedad con el regante'), lo que cuestiona la coherencia discursiva del ideario hidráulico y afecta a la cohesión de sus bases sociales.

Respuesta a los factores de crisis al calor de la cancelación del trasvase del Ebro (2004): «Agua para todos»

La reacción/renovación del paradigma hidráulico frente a estos embates es la característica clave de la etapa de elaboración y derogación del PHN(1996-2006). 
Un factor fundamental de esta reacción es el fortalecimiento de la funcionalidad del discurso hidráulico como cemento del bloque político-social hegemónico; un bloque que contribuye a crear rasgos identitarios regionales, muy débiles hasta ese momento, de los que se beneficia por medio del mensaje 'Agua para todos'. Este discurso todavía es capaz de arrastrar a las bases sociales y a las estructuras del sindicalismo obrero y campesino (CCOO, UGT, COAG, UPA). La participación activa de estos sectores en los 'acontecimientos discursivos' auténticamente aglutinadores (las grandes controversias que calan en la opinión pública, las movilizaciones sociales masivas) es un aspecto clave de esta etapa.

La historia de nuestra Autonomía se configura en gran parte en torno al agua (Del Toro (presidente de CROEM), Comparecencia ante la Comisión Especial de Estudio para el Pacto del Agua, Asamblea Regional de Murcia, 22 de febrero de 2007).

Yo le dije a Aznar que en el mitin debía ser muy claro y contundente con el tema del agua, como así fue, para tratar de que el PSOE al día siguiente entrara al trapo, y entró [...] Los medios de comunicación se encargaron de mostrar a la sociedad el enorme contraste entre las posiciones de Aznar, que garantizaba el nuevo trasvase, y de Rodríguez Zapatero, que prometía agua sin concretar cuándo ni de dónde vendría [...] Al segundo día de la campaña sabía que teníamos el 50\% de la victoria, comenta Valcárcel (Entrevista a Ramón Luis Valcárcel, después de haber sido reelegido como Presidente de la Región de Murcia, en las elecciones autonómicas de 2003, en La Verdad, 27 de mayo de 2003).

A diferencia de otras comunidades autónomas, la Región de Murcia no cuenta con ningún partido nacionalista, ni se había dotado hasta ahora de una imaginaria identidad nacional, ni se había afirmado frente a otras comunidades como un nosotros unitario y excluyente (...) Pero este nuevo sentimiento se asienta sobre una seña de identidad muy peculiar: el agua, convertida en el gran tótem comunitario de los murcianos mediante la simple y reiterada consigna del agua para todos (Foro Ciudadano, «El nacionalismo hidráulico», La Verdad, 21 de julio de 2005.

Se mantiene el papel de la legitimidad del regadío en la cohesión del discurso, pero se afronta la dificultad explicar públicamente el cambio de prioridad desde la agricultura al turismo residencial. ¿Complementariedad entre ambos sectores o sustitución de la primera por el segundo?

Se está produciendo una reubicación de sectores económicos, pasando de lo agrario a lo urbanístico. Hay importantes grupos empresariales de origen agrario, volcados en la construcción, como el grupo Durán. El estrangulamiento de la agricultura, está dando lugar a la expansión urbanística [...] La industria agroalimentaria no depende de la producción local [...] Todo esto hace viable la reconversión hacia el turismo y hacia el turismo-residencial, entendido como 
sector de nivel alto-medio, que permite una ocupación media del 30\%-40\% a lo largo del año, con servicios de todo tipo que dan actividad estable (Manuel Buitrago Bernal, periodista de La Verdad, entrevista, julio 2006).

Los resorts son compatibles con la agricultura. Murcia llega tarde al turismo residencial. Andalucía, ya tiene 80 campos de golf, y se espera pronto 100. En Murcia, sólo hay 5. Los ejemplos de Valencia y Alicante son muy ilustrativos. Murcia, por llegar tarde, puede evitar errores. La empresa Polaris es un ejemplo favorable. El mercado es Europa. Hagámoslo de forma ordenada [...] No hay que demonizar el turismo residencial [...] Es necesario mejorar la mala imagen que se ha creado (Clemente García García, CROEM, entrevista, julio de 2006).

Un hecho fundamental para la gestión del agua en destinos turísticos responde a las nuevas tendencias en el desarrollo de la actividad [...]. Los efectos de nuevas ofertas en áreas especializadas (caso del golf en las áreas del litoral), la puesta en marcha de grandes proyectos urbano-turísticos en tramos costeros hasta ahora no impactados, o la diversificación que justifica el despegue de municipios rurales, e incluso situados dentro de espacios naturales protegidos, son realidades a valorar en la proyección de demandas en horizontes futuros (Espejo Marín, 2004: 93).

\section{LAS CONTINUIDADES DEL DISCURSO DE LA MODERNIZACIÓN PRODUCTIVISTA}

Como datos fundamentales del momento actual y factores clave de su proceso de evolución destacan los siguientes temas:

1. La centralidad del debate de política del agua en la arena política y social regional sigue siendo una característica fundamental, imprescindible para contextualizar las posiciones y argumentaciones de los diferentes agentes sociales sobre el agua. Las reivindicaciones sobre el agua se han constituido en el núcleo articulador de una nueva o renovada 'identidad regional'; se asume expresamente la centralidad política del debate sobre el agua y de su repercusión directa en la contienda electoral. Durante las últimas décadas las ideas, posiciones y agrupaciones de los diferentes agentes sociales sobre temas económicos, sociales y culturales han estado condicionados por su posicionamiento ante los temas centrales del debate sobre el agua.

2. Pese a estar socavadas por los nuevos datos de la realidad (nuevas tecnologías, nuevos usuarios, nuevos contextos institucionales: mercados, precios, acuerdos comerciales), los topoi -esos estereotipos culturales que se transmiten y se utilizan de forma colectiva y que forman las premisas obligatorias de la argumentación- se mantienen. Entre ellos destacan: 
- La percepción del carácter vital del agua, su consideración como elemento de primera necesidad, incluyendo los usos realmente vitales y aquellos, también legítimos, pero que no lo son (actividades productivas, fundamentalmente regadío).

- El concepto de 'déficit estructural' relacionado con la alta valoración de la totalidad de la actividad agraria como sector esencial.

- El carácter ejemplar (eficiencia, productividad) de la gestión del agua en Murcia, a pesar de lo cual el déficit hídrico estructural persiste.

- El concepto de 'sostenibilidad', entendido como 'reequilibrio de oferta y demanda', reequilibrio que, a su vez, remite al incremento de oferta para satisfacer las demandas existentes, que se siguen considerando 'variables independientes'.

- La percepción del 'derecho de los murcianos' a que el Estado garantice el agua que demanda el regadío y la confrontación entre este 'derecho' y la 'insolidaridad' de otros territorios, lo que exige la unidad de todos los murcianos.

\section{LA DINÁMICA ACTUALES DE CAMBIO}

Tras la modificación del PHN y la cancelación del proyecto del trasvase Ebro, la estrategia del 'nacionalismo hidráulico' y la campaña del 'Agua para todos' llega a su apogeo, pero, al mismo tiempo, comienza vislumbrase sus límites, que se manifiestan en los siguientes desplazamientos significativos:

\section{La nueva centralidad del debate sobre el Tajo-Segura}

La polémica sobre la política de trasvases entre cuencas se desplaza desde el Ebro-Segura al trasvase Tajo-Segura (ATS). La continuidad del ATS empieza a ser cuestionada en la comunidad de Castilla-La Mancha, no solo por sectores sociales progresivamente más amplios sino por las instituciones locales y regionales. Al mismo tiempo, la 'irreversibilidad de la cancelación del trasvase el Ebro' va calando entre los agentes sociales de la propia cuenca del Segura (Hernández-Mora et al. 2014). Esto conduce a la emergencia de una prioridad insospechada en la etapa anterior: la necesidad de defender el ATS, hasta ahora fuera de cuestión. Aunque desde los sectores que sostienen con mayor tenacidad el ideario hidráulico no se renuncia a enarbolar la perspectiva del trasvase del Ebro (lo que, por ejemplo, ocasiona la falta de acuerdo en torno al Pacto del Agua de 2007), el debate sobre el futuro del Tajo-Segura va adquiriendo centralidad. 
Reforma de los Estatutos de Autonomía y sus implicaciones en las competencias sobre el agua

En segundo lugar, todas las comunidades autónomas (CCAA) afectadas por posibles trasvases, sea como donadoras o como receptoras de caudales, tratan de impedirlos o garantizarlos por la vía de la reforma de sus respectivos estatutos autonómicos (Mellado, 2010). Este proceso pone de manifiesto no sólo la dificultad de las CCAA para llegar a acuerdos duraderos entre ellas, sino también la facilidad con la que el discurso del 'nacionalismo hidráulico' se replica a sí mismo y es susceptible de ser utilizado por todos los gobiernos autónomos. De modo que, en cierta medida la estrategia del victimismo y la confrontación con otras CCAA (Cataluña, Aragón y Castilla-La Mancha) se vuelve en contra de la cuenca del Segura, cuyos portavoces tradicionalmente han defendido el marco estatal de decisión. En este contexto, en la Región de Murcia se evitó abrir el debate público y la negociación política sobre la reforma del Estatuto de Autonomía, como se hizo en la mayor parte de las restantes CCAA.

\section{Desde debate sobre los trasvases al debate sobre la desalación}

En tercer lugar, el debate sobre los trasvases se ve parcialmente reemplazado o complementado por el debate sobre la desalación, cuya significación en la nueva etapa histórica de la política del agua en España suscita una fuerte controversia (March, Rico y Sauri; 2014; Swyngedouw, 2015). Aunque la desalación llevaba tiempo contemplándose como una alternativa plausible para los desarrollos urbanos y la agricultura intensiva (García Lázaro, 1995, Espejo Marín, 2004), la reacción de la 'coalición discursiva hidráulica' fue rechazarla como alternativa al trasvase del Ebro, oponiéndose al desarrollo del programa AGUA. En 2007, los acontecimientos que rodearon la construcción de la planta de Torrevieja actualizaron ese debate, en este caso con el protagonismo del Gobierno autónomo valenciano.

Aunque con reservas respecto de los precios y exigiendo garantías de mantenimiento de las aportaciones externas a la cuenca, es indudable el cambio de lenguaje del conjunto de agentes sociales implicados en relación con la desalación. La evolución del discurso sobre la desalación transita desde la oposición frontal y la defensa del trasvase del Ebro hasta el debate sobre condiciones y precios.

La primera posición se escenifica en el voto en contra por parte de los regantes al Esquema de Temas Importantes (ETI) del primer plan de cuenca del Segura (2009), como expresión de la oposición a que se incluyera la desalación como alternativa. La segunda, el debate del verano de 2015, cuando lo que se reclama es un 'precio social' para la desalación, destinándose fondos del Decreto de Sequía para construir las conducciones desde las desaladoras a las zonas de 
riego (Decreto de sequía en la DH del Segura, RDL 356/2015). Es de destacar que mientras el SCRATS desde un posición pragmática reclama el «precio social» del agua desalada, siempre insistiendo en que sigue siendo necesario el trasvase para 'mezclar el agua', los agentes políticos se resisten a aceptar la desalación como solución (aunque apoyen el 'precio social' que reclama el SCRATS) porque aceptar la desalación sería 'claudicar' en este aspecto clave de su discurso histórico (comunicación de Nuria Hernández-Mora y Julia Martínez Fern).

Del debate sobre los trasvases a la controversia sobre los contratos de cesión y los bancos de agua

Otro de los temas de debate que ha experimento un cambio significativo en la etapa reciente es el de la 'flexibilización de concesiones' y los 'mercados del agua'. Estas mismas expresiones propias del debate inicial en la segunda mitad de la década de los 90, han sido sustituidas en el debate entre los agentes por las expresiones de 'contratos de cesión' y los 'bancos de agua' o la más precisa de 'centros de intercambio de derechos'. El aumento de los mensajes favorables a su aplicación es creciente (Hernández-Mora y del Moral, 2015), en una cuenca con una larga experiencia de mercados opacos de agua, rodeada de una polémica social y judicial ('el robo del agua').

Las reasignaciones de agua afectadas por las transacciones realizadas o previstas se refieren en todo caso a incorporaciones de aguas del Tajo al sistema del Regantes del Tajo-Segura (SCRATS) o de los Canales del Taibilla (MCT). Con respecto a las transacciones con el exterior, los agentes sociales realizan una valoración positiva, aunque relacionándola, por una parte, con el debate sobre las 'interconexiones de cuencas', lo que permite seguir insistiendo en la prioridad de los trasvases de otras cuencas; y por otra, con la discusión sobre la naturaleza del agua como 'recurso de dominio público', una forma de expresar las reservas de los agricultores frente a la 'mercantilización' de un 'recurso especial' (del Moral y Silva, 2006), que en la práctica está patrimonializado en concesiones muy rígidas.

Por el contrario, las transacciones internas entre usuarios de la propia cuenca del Segura siguen rodeadas de la polémica que produce la reasignación de recursos hídricos desde la agricultura a actividades de mayor productividad y capacidad de pago (usos residenciales) pero de menor legitimidad social, así como, más recientemente, a la reasignación de recursos hídricos entre regadíos y agriculturas de muy diferente naturaleza. Desde 2013 se han firmado contratos de compra-venta de aguas entre los regadíos tradicionales (Huerta de Murcia) y los regadíos intensivos de Mazarrón y Águilas, que han sido cuestionados, incluso judicialmente, por parte de sectores de regantes tradicionales que consideran 
ilegítima la cesión de derechos de agua desde los regadíos tradicionales, cuyo derecho de acceso al agua cuenta con un nivel de prioridad superior. En los años 2014-2015 el conflicto por la venta de agua de las huertas tradicionales ha aflorado con fuerza a raíz de los intentos de cesión de agua desde los regadíos tradicionales de la Vega Baja a los regantes del SCRATS, al amparo del Decreto de Sequía de 2015 (Hernández-Mora y del Moral, 2015).

\section{Desde el debate sobre el agua, a la controversia sobre el modelo de desarrollo urbanístico-territorial}

Durante los primeros años del siglo, en pleno boom inmobiliario, tuvo lugar un cambio importante en la controversia pública regional: el 'debate sobre el agua' en cierta medida comenzó a transformarse en el 'debate sobre el ladrillo'. Las nuevas demandas de agua ya no se vinculaban tanto a la agricultura como al desarrollo urbano-turístico.

Perico el Colorao, un conocido regante de la Vega Media, tuvo el atrevimiento y la valentía de exhibir un cartel donde rezaba: por cada metro que se urbaniza, un gotero que se cierra. Algunos de quienes estaban a su alrededor le reprocharon la consigna para recordarle que el motivo de la protesta era la defensa del Tajo-Segura, y no precisamente los complejos turísticos. Le recriminaron que con ese mensaje hacía mucho daño a la causa del agua... (La Verdad, 18 de julio de 2005).

El discurso del paradigma hidráulico se mostró vulnerable al mensaje de que la "sed de agua' es, en realidad, 'sed de golf" (título del polémico documental emitido en 2002 por TVE dentro del programa Línea 900 y que suscitó la indignación de amplios sectores de la sociedad murciana y el aplauso de otros).

En esa etapa, a través de la constitución del Ente Público del Agua (EPA), el Gobierno Regional reconoció abiertamente que las desaladoras que proyectaba estaban destinadas a satisfacer las demandas de la expansión inmobiliaria. En este contexto, el discurso del 'nacionalismo hidráulico', que había servido para movilizar a los agricultores ( $\mathrm{y}$, en general, a una población murciana que ya no es mayoritariamente agrícola, pero que conserva la memoria de un largo pasado rural), muestra su vulnerabilidad a una línea de crítica ('se está instrumentalizando a los agricultores'), línea que se fortalece a lo largo de la etapa más reciente.

En los años del boom se produjo una notable atención mediática nacional e internacional a la explosión inmobiliaria. Algunos de los temas especialmente emblemáticos fueron la desprotección de la Marina de Cope; la construcción de la autopista Cartagena-Vera, la saturación del Mar Menor, los proyectos para el Valle de Ricote, el proyecto de urbanización de Polaris en Alhama de Murcia o el caso de La Zerrichera (Aguilas). El debate se introdujo en el sector agrario: se 
lanzaron mensajes de defensa de los agricultores individuales como propietarios de suelo, comprendiendo sus motivaciones ('ofertas económicas irresistibles') para la enajenación de sus explotaciones, a la vez que se defendía la viabilidad y el carácter estratégico del sector.

\section{Incertidumbres sobre la evolución del sector agrícola}

Al final, el laberinto de la controversia desemboca en el nudo gordiano de las demandas agrarias: la dimensión y la intensidad del regadío.

El problema es que la agricultura sigue en el túnel; sin más opciones que esperar no se sabe qué exactamente (Manuel Buitrago, La Verdad, 26 de enero 2007).

[...] ¿qué pasa con la política agraria? Hay que reestructurarse, pero ¿cuáles con las directrices? [...] Hace falta una planificación de cultivos, diciendo qué hay que cultivar, y si hay que quitar 100.000 ha que lo digan. (Francisco del Amor, Presidente del SCRATS, Comisión del Pacto del Agua, 30 de noviembre de 2006).

Desde las instituciones se ha defendido la necesidad de una 'paulatina reestructuración del regadío', sin cuantificar ni programar. Una perspectiva que se refleja en escritos, declaraciones formales y comentarios informales en el sentido de que la desalación, acompañada de la regeneración y reutilización, unida a la reducción de superficie regada y de demandas agrarias a consecuencia de la expansión urbanística y la reestructuración de cultivos, puede conducir a un 'equilibrio razonable': «En una década el balance se va a reequilibrar». Desde esta perspectiva, se insiste en que ya está en marcha un reequilibrio a la baja de la superficie de regadío. El regadío se incrementa en Albacete (Hellín), pero «no de una manera preocupante» (viñedo, olivar, consumos locales). Se trataría, además, de zonas desfavorecidas. Según estas opiniones, se cuenta con una mejor información (Alberca, teledetección, SIGs) que confirmaría estas tendencias (entrevistas con Manuel Aldaguer y Mario Urrea, CHS, 2006 y 2007).

La verdad se acerca más a la realidad de una creciente dicotomía entre los regadíos tradicionales, en contracción desde hace décadas, y los 'nuevos regadíos', en los que la dinámica de la superficie regada responde a parámetros diversos (precios de mercado, posibilidades de comercialización, episodios climáticos...). En el verano de 2014, por ejemplo, José Manuel Claver, Presidente del Sindicato Central de Regantes, declaraba que los regantes del ATS habían incrementado la superficie de regadío ese año en un $20 \%$, habiendo plantado 'hasta en las terrazas' (La Verdad, 14 septiembre 2014)

En este sentido es significativo el debate en profundidad que se abrió en la Mesa sobre el agua del Plan Estratégico 2007-2015 (Horizonte 2015). A partir de la premisa de la imposibilidad de resolver el déficit con nuevos recursos, el documento planteaba la necesidad de establecer criterios y marcos reguladores 
para la «transferencia de agua entre distintos usos que compiten entre sí», con la máxima transparencia y la inclusión de criterios medioambientales y paisajísticos. En el apartado final del documento, se presentan los factores clave de cambio para conseguir los diferentes escenarios posibles, entre ellos 'un mercado transparente del agua'. En relación con el establecimiento de este 'mercado' el documento proponía dos líneas clave de actuación: «la correcta y sistemática contabilización del agua usada, en todos los usos» $\mathrm{y}$ «una liberalización del mercado que permita actuar a los operadores libremente, en igualdad de condiciones y sin restricciones imprevistas por intervencionismo político» (Consejería de Economía y Hacienda, 2006). La evolución de los acontecimientos, como se ha comentado anteriormente, apuntan en esta dirección (Hernández-Mora y del Moral, 2015).

\section{De la hegemonía del regadio a la irrupción del abastecimiento, sus nuevos discursos y actores sociales}

Paralelamente a esto, el cambio más notable de los últimos años ha sido la irrupción de nuevos temas (equidad social, gestión pública...), nuevos discursos ('derecho humano al agua', 'garantía de suministros básicos', 'auditoria social del agua') y nuevos actores sociales (sectores ciudadanos, partidos emergentes). Los movimientos contra la privatización del agua y su gestión, de larga tradición en Latinoamérica y otros continentes, se han extendido por Europa y, en los últimos años, han penetrado en España de la mano de la Red Agua Pública (RAP) (Giménez y Babiano, 2014).

En la Región de Murcia durante los últimos veinte años se ha ido privatizando la gestión de los servicios municipales de abastecimiento y saneamiento, de forma que en la actualidad más del $85 \%$ están gestionados por empresas privadas. En un número significativo de ocasiones, los municipios con el servicio privatizado han cortado el suministro a las familias que no han podido pagarlo. En la etapa más reciente han surgido controversias en municipios como Santomera, Lorca, Cartagena y Las Torres de Cotillas y un claro movimiento de oposición en La Unión. A principios de 2014 se creó la Asamblea Agua Pública 100\% Región de Murcia, centrada en la defensa del 'Derecho Humano al agua', 'la remunicipalización' y el 'control democrático' de los servicios municipales de aguas' (Foro Ciudadano Región de Murcia, 2014:141-142). Sin duda, estos planteamientos están introduciendo nuevos discursos sobre el agua en el Segura.

\section{CONCLUSIONES}

En la cuenca del Segura, y de manera especial en su núcleo, la Región de Murcia, se expresan con la máxima intensidad y persistencia los procesos socio-ambientales que dan lugar ideario del hidráulico. Pese a ello, también 
aquí los cambios en las funciones económicas asignadas al sector primario, su significación en la producción, su estructura empresarial y laboral, así como el desarrollo de nuevos sectores productivos, aunque carezcan de la legitimidad social del regadío, hacen que las argumentaciones vayan transformándose. En este sentido, la evolución de los debates científicos y sociales, ya desde hace tiempo, reflejan el progresivo aunque lento desarrollo de visiones propias de la 'sociedad reflexiva' (Giddens, Beck y Lash, 1994), que implica la sustitución del ideal de dominación de la naturaleza por fórmulas de relación sociedadnaturaleza más flexibles y adaptativas.

El reconocimiento y aprecio por los escenarios semiáridos de la región, la revalorización y correcto uso de estos ambientes, promover comportamientos sostenibles y reconciliar a los habitantes con los paisajes áridos de su entorno, serían eficaces acciones para mitigar los efectos de la aridez y la sequía $[\ldots]$ (López Bermúdez, 2001: 187).

Estrechamente relacionado con este proceso, se presenta un aspecto clave de la situación actual en el Segura: el discurso hegemónico en una formación social determinada se caracteriza consustancialmente por su 'capacidad de estructurar' a amplios y diversos sectores sociales en 'coaliciones discursivas' que sobrepasan los límites de intereses inmediatos y concretos; esta cualidad se acompaña de la 'potencialidad de institucionalizar', dar una existencia propia y autónoma, no inmediatamente dependiente de los agentes sociales concretos, a los acuerdos y reglas de funcionamiento que se sostienen (Hajer, 2005). Pues bien, esta capacidad de estructurar e institucionalizar por parte del discurso hidráulico hegemónico se viene debilitando en la última década. Algunos agentes sociales (sindicatos, organizaciones agrarias y ciudadanas), fieles integrantes de la 'coalición discursiva' hasta hace poco se distancian del ideario hidráulico, solicitan mayor ponderación en los mensajes; piden a las fuerzas políticas acuerdos entre ellos; entienden que el enfrentamiento, enmarcado en una confrontación política general, de la Región de Murcia con otras comunidades autónomas no favorece los intereses sectoriales, ni de corto ni de largo plazo.

Sin embargo, aunque el discurso del «Agua para todos» está actualmente debilitado, sigue teniendo la capacidad de impedir el disenso. Es cierto que no existe el alineamiento que dominaba en la primera década del siglo, pero sigue sin haber discrepancia explícita. La percepción de que se trata de un discurso que esconde intereses distintos de los generales ha ido ganando espacio en la percepción pública; las divisiones entre los sectores del regadío, en torno a temas emergentes como los mercados del agua, se agudizan. Pero todavía no aflora un discurso con amplio apoyo social. Las potencialidades de seguir estructurando mayorías sociales en torno a argumentos de identidad regional cementadas en la reivindicación del agua siguen vigentes. 
Por el contrario, el debilitamiento, posiblemente irreversible en un horizonte previsible, del Estado central como protagonista de la gran política hidráulica, en un contexto de consolidación de competencias autonómicas (Aragón, Castilla-La Mancha) sobre recursos propios progresivamente más escasos, debilita los contenidos materiales de la tradicional reivindicación de recursos externos. Las movilizaciones sociales inéditas en Castilla-La Mancha (gran manifestación en Talavera de la Reina en junio de 2009, movilizaciones en toda la cuenca del Tajo en septiembre de 2015) auguran una resistencia y conflictividad creciente desde la cuenca cedente (Hernández-Mora, 2013). Los sucesos (tensiones, recursos, sentencias) que han rodeado la elaboración del Memorándum acordado entre el Ministerio de Agricultura, Alimentación y Medio Ambiente y las comunidades autónomas de Murcia, Valencia, Castilla La Mancha, Madrid y Extremadura (octubre 2013), la Ley 21/2013, de 9 de diciembre, de Evaluación Ambiental y la Ley 21/2015, de 20 de julio, por la que se modifica la Ley 43/2003, de 21 de noviembre, de Montes, tampoco despejan el horizonte del ATS.

Desde el punto de vista de los nuevos argumentos emergentes, de las narrativas y temas emblemáticos que pueden definir 'coaliciones discursivas' alternativas, son de especial interés los intentos de racionalización del debate sobre las diferentes funciones del agua. Se solicita diferenciar entre las funciones vitales (incluidas ecológicas), las sociales (incluidas las patrimoniales) y las funciones productivas (incluidos todos los sectores). Aunque estos intentos chocan con la larga tradición de utilización de los 'mitos' que rodean al agua, por parte del ideario hidráulico, es indudable que existe una creciente demanda de planteamientos explícitos sobre la necesidad de una 'reestructuración ordenada del regadío', en los que se explicite qué debe seguir existiendo, en qué condiciones, con qué objetivos; $y$, en su caso, qué debe de ser desafectado, dónde, con qué criterios, con qué ritmos y con qué medidas de compensación.

Finalmente, los nuevos discursos ciudadanos sobre el 'derecho humano al agua' ('agua pública', 'suministros básicos garantizados'), que expresan nuevas demandas al calor de la onda expansiva de la larga recesión económica y sus reacciones sociales, están construyendo argumentos alternativos a la bandera de la 'solidaridad territorial' (concretadas en trasvases entre cuencas), que ostenta el ideario hidráulico.

\section{FUENTES}

Ayuntamiento de Murcia (2007): Declaración del Municipio de Murcia en el día mundial del agua 2007, Murcia.

Bautista MARtín, J. (1992): «Del Plan de Mejora y Ampliación de los Riegos de Levante al Aprovechamiento conjunto Tajo-Segura», en A. Gil Olcina y A. Morales GIL (coords.): Hitos históricos de los regadíos españoles, MAPA, Madrid, pp. 365-396. 
Calvo Garcia-Tornel, F. (1984): «Le bassin du Segura: une expansion problématique de l'irrigation dans le sud-est de L'Espagne», Revue Géographique des Pyrénées et du Su-Ouest, vol. 55, núm. 4, pp. 477-494.

Calvo García-Tornel, F. (2006): «Sureste Español: regadío, tecnologías hidráulicas y cambios territoriales», en VII Coloquio Internacional de neocrítica, Geografía Histórica e Historía del Territorio, México.

Canales, G. (2002): «Implicaciones sociales del agua en la Vega Baja del Segura (Alicante)», en J. Cánovas (coord.) La CHS, 1926-2001. 75. Aniversario, Murcia.

Coag-Ir Murcia (2006): Posicionamiento de COAG-IR Murcia ante el Documento de la Mesa de Trabajo Recursos Hídricos y Ordenación del Territorio del Plan Estratégico de la Región de Murcia, 2. ${ }^{a}$ Ronda.

Colegio de Geógrafos (2008): «Procesos territoriales y agua en la cuenca del Segura», en Ambienta, febrero 2008, n. ${ }^{\circ} 74$, pp. 61-67.

Consejería de Economía y Hacienda de la Región de Murcia (2006): Plan Estratégico de la Región de Murcia. Mesa de Trabajo de Recursos Hídricos y Ordenación del Territorio, 2. ${ }^{a}$ Ronda, TECNOMA-Red2Red Consultores.

Consejo Económico y Social de la Región de Murcia (2000): Informe sobre la reforma de la PAC y el sector agrario de la Región de Murcia, Murcia, Consejo Económico y Social.

Consejo Económico y Social de la Región de Murcia (2006): La ordenación del territorio en la Región de Murcia. Estado actual de la materia, Murcia, Consejo Económico y Social.

EsPejo MARín, C. (2004): «Campos de golf y medio ambiente: una interacción necesaria», Cuadernos de turismo, 14, pp. 67-111.

Esteve Selma, M.A. (2002); «Implicaciones ambientales de la gestión del agua en las cuencas receptoras del trasvase Ebro-Júcar-Segura, especialmente en las tierras del Sudeste Ibérico», en P. Arrojo y L. DEL Moral (coords.) III Congreso Ibérico sobre Gestión y Planificación del Agua, Institución Fernando el Católico, Zaragoza, pp.

FAIRCLOUGH, N. (2003): «El análisis crítico del discurso como método para la investigación en ciencias sociales», en R. WodaK y M. Meyer (comp.) Métodos de Análisis del Discurso, Gedisa, Barcelona, en pp. 179-2003.

FERNÁNDEZ, S. (2005): «La participación pública en la ordenación del paisaje. Una reflexión a partir de tres proyectos en la Región de Murcia», en Mata Olmo, R. y Torroja (dirs.): El paisaje y la gestión del territorio, Diputación de Barcelona, Barcelona.

Foro Ciudadano Región de Murcia (2003, 2006, 2010, 2014): El otro estado de la Región, Informe 2003, Informe 2006, Informe 2010, Informe 2014, DM Librero Editor, Murcia.

García LÁzaro, U. (1995): Estudio de posibilidades de instalación de plantas desalinizadoras con aguas subterráneas de los acuíferos del Campo de Cartagena, Informe para la Federación de Cooperativas Agrarias de la Región de Murcia.

GimÉnez, M. y Babiano, L. (2014): «El Derecho Humano al Agua», Revista El Ecologista, núm. 81. http://www.ecologistasenaccion.org/article27970.html 
Anthony Giddens, Ulrich Beck and Scott Lash (1994): Reflexive Modernization: Politics, Tradition and Aesthetics in the Modern Social Order, Stanford University Press.

Gil OlcinA, A. (2000): La propiedad de aguas perennes en el Sureste Ibérico, Biblioteca Virtual Miguel de Cervantes, Alicante.

Gil Olcina., A. y A. Morales Gil (ed.) (2001): Causas y consecuencias de las sequías en España, CAM, Instituto Universitario de Geografía, Alicante.

Gómez Mendoza, J. y L. Moral Ituarte del (1995) El Plan Hidrológico Nacional: criterios y directrices, en Gil Olcina, A. y Morales Gil, A. (eds.), Planificación Hidráulica en España, Fundación Caja del Mediterráneo, Alicante, pp. 331-378.

HaJer, M. A. (1995) The Politics of Environmental Discourse: Ecological Modernisation and the Policy Process, Clarendon Press, Oxford.

Hernández-Mora, N. (Coord.) (2013): El Tajo. Historia de un rio ignorado, Fundación Nueva Cultura del Agua, Zaragoza.

Hernandez-Mora, N. y DEL Moral, L. (2015): «Developing markets for water reallocation: Revisiting the experience of Spanish water mercantilización», Geoforum 62 (2015), pp. 143-155.

Hernández-Mora, N, Del Moral L, La Roca F, La Calle A, Schmidt G. (2014): «Interbasin water transfers in Spain. Interregional conflicts and governance responses». In G Schneier-Madanes (ed.) Globalized water, Dordrecht, Germany: Springer.

JÄGER, S. (2003): «Discurso y conocimiento: aspectos teóricos y métodológicos de la crítica del discurso y del análisis de dispositivos», en R. Wodak y M. Meyer (comp.) Métodos de Análisis del Discurso, Gedisa, Barcelona, en pp. 61-100.

López Bermúdez, F. (1985): Sequía, aridez y desertificación en Murcia, Academia Alfonso X El Sabio, Murcia.

López ONTIVERos, A. (1998): «El regadío, salvación de la patria y fuente de felicidad, según los congresos nacionales de riegos (1913-1934), Demófilo. Revista de Cultura Tradicional de Andalucía, n. ${ }^{\circ} 27$, pp. 27-64.

March, H., SAurí, D., Rico-Amorós, A. (2014): «The end of scarcity? Water desalination as the new cornucopia for Mediterranean Spain», Journal of Hydrology, núm. Part C, Pág. 2642-2651

Martínez Fernández, J. y Esteve Selma, M.A. (coords.) (2002): Agua, regadio y sostenibilidad en el Sudeste Ibérico, Bakeaz, Bilbao.

Martínez Fernández, J. y Esteve, M.A. (2005): «A critical view of the desertifacion debate in Southeasthern Spain», Land Degradation and Development, 16 (2005), pp. 529-539.

Meyer, M. (2003): «Entre la teoría, el método y la política: la ubicación de los inforques relacionados con el ACD», en R. Wodak y M. Meyer (comp.) Métodos de Análisis del Discurso, Gedisa, Barcelona, en pp. 35-60.

Mellado Ruiz, L. (2010): Aguas y ordenación del territorio en el contexto de la reforma estatutaria, Comares, Granada.

Moral Ituarte, L. Del (2000) «Problemas y tendencias de la gestión del agua en España: del proyecto Borrell al proyecto Matas», in Estevan, A. y V. Viñuales, 
La eficiencia del agua en las ciudades, Bakeaz-Fundación Ecología y Desarrollo, Bilbao, pp. 13-52.

Moral ItUarte, L. Del y R. Silva PÉrez (2006): «Grandes zonas regables y reparto del agua en España. El caso de la cuenca del Guadalquivir». Mélanges de la Casa de Velázquez, número monográfico «Partage de l'eau en Espagne, au Portugal et au Maroc», n. ${ }^{\circ} 36$ (2), pp. 125-148.

Morales GiL, A. (1999): «El consumo agrícola de agua. Sus modalidades y trascendencia socioeconómica actual», en Gil Olcina, A. y Morales Gil, A. (eds.), Los usos del agua en España, Caja de Ahorros del Mediterráneo, Instituto Universitario de Geografía, Alicante, pp. 49-79.

Morales Gil, A. (2001): Agua y Territorio en la Región de Murcia, Fundación Centro de Estudios Históricos e Investigaciones Locales Región de Murcia, Murcia.

Morales Gil A. y Hernández Hernández M. (2010): «Mutaciones de los usos del agua en la agricultura española durante la primera década del siglo XXI. Investigaciones Geográficas, n51, p. 27-51.

Morales Gil, A., Rico Amorós, A.,, J. Olcina Cantos (1996) «Enseñanzas de las sequías en el sureste ibérico» in Marzol, M.V., Dorta, P. and Valladares, P. (eds.) Clima y agua: la gestión de un recurso climático, La Laguna, pp. 211-223.

Ojeda Rivera, J.J. y L. Del Moral Ituarte (2004 o2005?): «Percepciones del agua y modelos de su gestión en las distintas fases de la configuración de Doñana», Estudios Geográficos, Instituto de Geografía, Universidad de Alicante, 35, pp. 25-44.

Olcina Cantos, J. (2003): «Desertificación: un mito inexistente», Información de Alicante, 25 de mayo de 2003.

Pedreño Cánovas, A., P. Baños Páez y B. Costantini (2006): «Construcción social y dimensión pública de las problemáticas medioambientales: una invitación a la sociología del desierto y del agua», en L. Camarero (coord.) Medio ambiente y Sociedad: elementos de explicación sociológica, ITES-Paraninfo, pp. 335-378.

Péréz-Díaz, V., Mezo, J. y Álvarez-Miranda, B. (1996): Política y economía del agua en España, Círculo de Empresarios, Madrid.

PÉrez Picazo, M. T. (2006): ««De campesino a ciudadano»: la difícil penetración de la ciudadanía activa en la sociedad murciana», en Foro Ciudadano Región de Murcia (2006): El otro estado de la Región, Informe 2006, DM, Murcia, pp. 19-32.

Pita, M.F., L. del Moral, B. Pedregal, N. Limones y N. Hernández-Mora (2014): «Nuevos paradigmas en la gestión de recursos y riesgos hídricos: datos e información necesarios para una gestión integrada del agua», Boletín de la Asociación de Geógrafos Españoles, núm. 65-2014, págs. 519-542.

Resolución de la Presidencia, de 25 de julio de 1994, por la que se publica el Pacto del Agua de la Región de Murcia, Borm, 3 de agosto de 1994.

Segura, P., A. Pedreño y de Juana (2002): «Configurando la Región Murciana para las frutas y hortalizas: racionalización productiva, agricultura salarial y nueva estructura social del trabajo jornalero», Áreas, 22, Murcia.

Senet Alonso, M. y F. Cabeza Calvo-Rubio (directores) (1995): Agua y Futuro en la Región de Murcia, Murcia, Asamblea Regional de Murcia. 
Sindicato Central de Regantes Acueducto Tajo-Segura (2006): Memoria 2005, Murcia.

Swyngedouw, E. (2015): Liquid Power. Contested Hydro-Modernities in TwentiethCentury Spain, The MIT Press, Cambridge, Massachusetts.

Vera Rebollo, J.F. (2006): «Agua y modelos de desarrollo turístico: la necesidad de nuevos criterios para la gestión de los recursos», Boletín de la Asociación de Geógrafos Españoles, 42, pp. 155-178.

VAN DIJK, T.A. (2003): «La multidisciplinariedad del análisis crítico del discurso: un alegato en favor de la diversidad» en R. Wodak y M. Meyer (comp.) Métodos de Análisis del Discurso, Gedisa, Barcelona, en pp. 143-178.

WodaK, R. (2003): «De qué trata el análisis del discurso (ACD). Resumen de su historia, sus conceptos fundamentales y sus desarrollos», en R. Wodak y M. Meyer (comp.) Métodos de Análisisi del Discurso, Gedisa, Barcelona, en pp. 17-34. 